\title{
Azathioprine in giant cell arteritis/polymyalgia rheumatica: a double-blind study
}

\author{
M DE SILVA ${ }^{1}$ AND B L HAZLEMAN ${ }^{2}$ \\ From the ${ }^{1}$ Prince Charles Hospital, Merthyr Tydfil, Mid Glamorgan, Wales; and the ${ }^{2}$ Department of \\ Rheumatology, Addenbrooke's Hospital, Hills Road, Cambridge
}

SUMmARY The ability of azathioprine to reduce the maintenance prednisolone requirement of $\frac{O}{\Omega}$ 31 patients with polymyalgia rheumatica (PMR) or giant cell arteritis (GCA), or both, was tested in a double-blind placebo controlled study over one year. Clinical and laboratory assessments were made at four-weekly intervals over a period of 52 weeks. A statistically significant iv difference $(p<0.05)$ in mean prednisolone dose was noted between the two groups at the end of $\vec{\omega}$ 52 weeks, there being a fall in steroid requirement in the azathioprine treated group.

Key words: suppressive therapy.

Corticosteriods are the only drugs with proved efficacy in the treatment of giant cell arteritis (GCA). They are also widely used in the treatment of polymyalgia rheumatica (PMR). Many consider GCA and PMR to represent different phases of the spectrum of the same clinical syndrome. ${ }^{1}$ Disease activity may persist for several years, ${ }^{2}$ requiring prolonged treatment with corticosteriods and increasing the risk of hypercorticism. The GCA/PMR syndrome is essentially a disease of the elderly, many of whom may also suffer from concomitant diseases, e.g., hypertension, diabetes mellitus, osteoporosis, congestive cardiac failure, which may be adversely affected by long term corticosteroid therapy. For these reasons an alternative to corticosteroid or a steroid-sparing agent for the treatment of PMR/GCA would be invaluable. On the basis of its proved steroid-sparing effect in rheumatoid arthritis $^{3}$ and its use in other connective tissue disease, azathioprine was selected as a suitable agent for further study. Reports of its efficacy or lack of it in GCA/PMR are mainly anecdotal. There are no reports of satisfactory clinical trials on the role of azathioprine in PMR/GCA.

We report the results of a controlled double blind study over 52 weeks in which we assessed the steroid-sparing effect of azathioprine in the GCA/ PMR syndrome.

Accepted for publication 24 July 1985

Correspondence to Dr M De Silva, Consultant Rheumatologist, Prince Charles Hospital, Merthyr Tydfil C47 9DT.

\section{Patients and methods}

Patients were included if the criteria of Jones and Hazleman $^{2}$ were fulfilled (Appendix). Thirty-ow patients receiving $5 \mathrm{mg}$ or more of prednisolone day were entered into the study. The dose of steroid had been reduced to a minimum sufficient to control symptoms, and this dose had remained stable for a $\mathbb{Q}$ minimum period of at least three months before the $\vec{F}$ start of the study. Seventeen of the 31 patients had $\frac{0}{3}$ concomitant disease, 12 were hypertensive, two had osteoporosis, and one each had thyrotoxicosis, congestive cardiac failure, or peptic oesophagitis. They had all been present for more than a year before the start of the study and appropriate treatment had been instituted.

Whenever possible patients were paired and stratified for age, duration of disease activity, $₹$ temporal artery biopsy positivity, and maintenance 의 dose of prednisolone. Each patient was allocated randomly by means of a code to receive either the음 active drug (azathioprine $50 \mathrm{mg}$ tablets) or matching placebo. Patient details are given in Table 1. Patients were assessed at the start of the study and $N$ after at four-weekly intervals for 52 weeks according $N$ to a standard protocol (Table 2). At second and subsequent visits both patient and clinician gave an

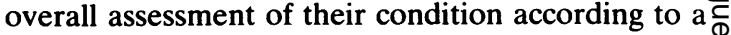
five-point scale. Laboratory assessment included $\stackrel{\oplus}{\longrightarrow}$ erythrocyte sedimentation rate (ESR, Westergren), 7 $\mathrm{C}$-reactive protein, and liver function.

Initially, all patients were given four weeks' 
Table 1 Patient details

\begin{tabular}{|c|c|c|}
\hline & Azathioprine & Placebo \\
\hline Number of patients & 16 & 15 \\
\hline Female/male & $11 / 5$ & $13 / 2$ \\
\hline \multicolumn{3}{|l|}{ Age (years) } \\
\hline mean & 69 & 70 \\
\hline range & $57-80$ & $59-79$ \\
\hline \multicolumn{3}{|l|}{ Disease duration (years) } \\
\hline mean & $2 \cdot 3$ & $2 \cdot 5$ \\
\hline range & $1-6$ & $0 \cdot 75-6$ \\
\hline Arterial biopsy positive & 5 & 6 \\
\hline
\end{tabular}

Table 2 Clinical assessment

1. Headache + or - and site

2. Muscle pain-site and severity (mild-moderate + severe)

3. Muscle stiffness (early morning) in minutes

4. Visual disturbances-nature and frequency

5. Jaw claudication $+/-$

6. Scalp artery tenderness and pulsation

7. Systemic symptoms-night sweats, fever, malaise, weight loss

supply of tablets and requested to take one tablet three times daily after meals while continuing with their other medication. All patients were given a supply of metoclopramide (Maxolon) tablets $(5 \mathrm{mg}$ ) and instructed to take them if they experienced nausea and asked to continue with the suggested dose unless side effects became unacceptable, when they could reduce to one tablet once or twice daily, or even discontinue their trial medication.

At each monthly assessment a note was made of any change in dose of trial medication. Patients were questioned for the occurrence of side effects and the dose of prednisolone altered by $1 \mathrm{mg}$ a day in the light of the overall clinical and haematological assessment.

\section{Results}

The time and reasons for withdrawal are given in Tables 3 and 4. Abnormalities in serum alkaline phosphatase, bilirubin, and alanine aminotransferase occurred only in the azathioprine treated group. These occurred either individually or in combination and resolved spontaneously or on reduction of the dose. Two patients receiving azathioprine developed macrocytosis, with mean corpuscular volume $>100 \mathrm{fl}$ at 12 and 40 weeks respectively. This abnormality persisted until the end of the study. No patients were withdrawn because of biochemical or haematological abnormalities. Nausea occurred in both groups of patients but was more severe in the azathioprine treated group. One patient developed severe vomiting and dehydration. Only patients completing a minimum of 36 weeks of the study were included in the statistical analysis.

Results of 10 of 16 patients in the azathioprine group and 12 of 15 in the placebo group were therefore available for analysis. Nine patients in the azathioprine group and 11 patients in the placebo group completed 52 weeks of the study. The steroid requirements of the two groups over the study period are given in Table 5 . The steroid requirement of both groups fell during the course of the study but was more pronounced in the azathioprine treated group. However, with the small numbers involved this difference reached statistical significance only at 52 weeks. Of the nine patients completing 52 weeks of the study, five were able to take $150 \mathrm{mg}$ of azathioprine/day and four $100 \mathrm{mg} /$ day (range 1.5 to $2.7 \mathrm{mg} / \mathrm{kg} /$ day).

Table 3 Reasons for withdrawal*

\begin{tabular}{lll}
\hline & Azathioprine & Placebo \\
\hline Nausea & 4 & 2 \\
Vomiting & 2 & - \\
Diarrhoea & 1 & 1 \\
$\begin{array}{l}\text { Collapse } \\
\text { Non-compliance }\end{array}$ & 1 & - \\
$\begin{array}{l}\text { Discontinued before surgery } \\
\begin{array}{l}\text { Total number of patients } \\
\text { withdrawn }\end{array}\end{array}$ & - & 1 \\
\hline
\end{tabular}

*Some patients showed more than one adverse effect at time of withdrawal.

Table 4 Timing of withdrawals

\begin{tabular}{rlllll}
\hline & \multicolumn{2}{l}{ Withdrawals } & & & \multicolumn{2}{c}{ Patients remaining in trial } \\
\cline { 5 - 6 } Weeks & Azathioprine & Placebo & & Azathioprine & Placebo \\
\hline $0-12$ & 6 & 1 & 10 & 14 \\
$12-24$ & - & 2 & 10 & 12 \\
$24-36$ & - & - & 10 & 12 \\
$36-52$ & 1 & 1 & 9 & 11 \\
\hline
\end{tabular}

Table 5 Prednisolone dosage*

\begin{tabular}{rlll}
\hline Weeks & Azathioprine & Placebo & $\begin{array}{l}\text { Statistical } \\
\text { significancet }\end{array}$ \\
\hline 0 & $8 \cdot 1 \pm 0 \cdot 37$ & $7 \cdot 4 \pm 0 \cdot 37$ & NS \\
12 & $5 \cdot 1 \pm 0 \cdot 37$ & $4 \cdot 8 \pm 0 \cdot 32$ & NS \\
24 & $3 \cdot 6 \pm 0 \cdot 58$ & $3 \cdot 7 \pm 0 \cdot 37$ & NS \\
36 & $2 \cdot 8 \pm 0 \cdot 69$ & $3 \cdot 3 \pm 0.46$ & NS \\
52 & $1 \cdot 9 \pm 0 \cdot 84$ & $4 \cdot 2 \pm 0.58$ & p $<0.05$ \\
\hline
\end{tabular}

*Values (in $\mathrm{mg}$ ) are mean $\pm \mathrm{SEM}$ for both groups.

†Using unpaired $t$ tests. 


\section{Discussion}

The difference in the reduction in mean steroid dosage between the two groups became significant only at 52 weeks. Although the small numbers available for statistical analysis may partly account for this, part of the explanation may lie in the slow mode of action of azathioprine. In this study no attempt was made to reduce the dose of azathioprine from $150 \mathrm{mg}$ a day, reductions being made only on the grounds of poor tolerance; none were required on the grounds of toxicity. This approach of maintaining a reasonable dose of azathioprine may be validated by the experience with steroids in the PMR/GCA syndrome, where a rapid reduction of steroid dose in the first year, irrespective of the initial dose, may lead to a recurrence of symptoms. The average dose of azathioprine in the present study was $1.5-2.7 \mathrm{mg} / \mathrm{kg} /$ day, this dose being determined mainly by patient tolerance. This compares with the dose of azathioprine of $1.25-2.5 \mathrm{mg} / \mathrm{kg} / \mathrm{day}$ used in the treatment of rheumatoid arthritis, though initial doses as high as $5 \mathrm{mg} / \mathrm{kg} /$ day have been used. ${ }^{4}$

Treatment with azathioprine for non-malignant conditions entails low dosage over prolonged periods and may result in subtle side effects. Immediate toxicity is unusual and matches the idiosyncracy seen with any drug. The major early complication is suppression of the bone marrow, and overdosage may result in an overwhelming opportunistic infection. Potential oncogenic effects of immunosuppressive drugs remain one of the main deterrents to their widespread use, though this risk is probably small. ${ }^{5}$ The relatively shorter period of exposure to the agent in this elderly group of patients compared with that required for the treatment of patients with rheumatoid arthritis or systemic lupus erythrmatosus may also mitigate potential oncogenic effects.

This steroid-sparing effect of azathioprine may be used to advantage particularly in those patients suffering from concomitant diseases which may be adversely affected by steroids and to reduce the side $\bar{C}$. effects of long term steroid therapy in those patients with PMR/GCA syndrome who require large doses $\stackrel{\vec{\Rightarrow}}{\vec{F}}$ of steroids not only for initial control of the diseasebut also for maintenance therapy.

We thank Wellcome Research Laboratories for supplying the azathioprine and placebo tablets and Miss S Roberts, Faculty of Community Medicine, University of Cambridge, for the statistical के analysis.

Appendix

Criteria for diagnosis of polymyalgia rheumatica

1. Shoulder and pelvic girdle pain which was primarily muscular in $\bar{\varrho}$ the absence of true muscle weakness.

2. Morning stiffness.

3. Duration of at least two months.

4. ESR over $30 \mathrm{~mm} / 1 \mathrm{st}$ h or C-reactive protein (CRP) over $6 \mu \mathrm{g} / \mathrm{ml} \vec{\omega}$ $(\mathrm{mg} / \mathrm{l})$.

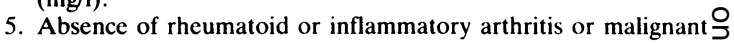
disease.

6. Absence of objective signs of muscle disease.

7. Prompt and dramatic response to corticosteroid therapy.

Criteria for diagnosis of giant cell arteritis

1. A positive temporal or other arterial biopsy.

2. Tenderness or absence of pulsation in cranial arteries, or both. $\overrightarrow{0}$

3 . One or more of the following: (a) visual disturbance, $\Phi)$ temporal or occipital headache, (c) jaw claudication.

4. ESR over $30 \mathrm{~mm} / 1 \mathrm{st}$ h or C-reactive protein (CRP) over $6 \mu \mathrm{g} / \mathrm{m}$ $(\mathrm{mg} / \mathrm{l})$.

5. Prompt response to corticosteroid therapy.

\section{References}

1 Hamrin B, Jonsson N, Hellsten S. 'Polymyalgia arteritica': further clinical and histopathological studies with a report of six $\overline{\widehat{O}}$ autopsy cases. Ann Rheum Dis 1968; 27: 397-405.

2 Jones J G, Hazleman B L. Prognosis and management of polymyalgia rheumatica. Ann Rheum Dis 1981; 40: 1-5.

3 Mason R M, Currey H L F, Barnes C G, Dunne J F, Hazleman:B L, Strickland I D. Azathioprine in rheumatoid arthritis. Brô Med $J$ 1969; i: $420-1$.

4 De Silva M, Hazleman B L. Long term azathioprine in rheumatoid arthritis: a double-blind study. Ann Rheum Dis 1981; 40: 560-3.

5 Hazleman B L. Neoplasms in rheumatoid arthritis. Am J Med 1985; (suppl 1A): 39-43. 